\title{
Analisis Strategi SOAR Balai Diklat Aparatur Kementerian Kelautan dan Perikanan Menuju Corporate University
}

\author{
Afnan Fuadi ${ }^{\mathrm{a}, 1 *}$ \\ ${ }^{a}$ Balai Diklat Aparatur; Kementerian Kelautan dan Perikanan \\ lafnanfuadi@kkp.go.id \\ *Jalan Raya 2 Sukamandi, Patokbeusi, Subang, Jawa Barat
}

Naskah diterima: 20 Februari 2020, direvisi: 15 Maret 2020, disetujui: 26 Maret 2020

\begin{abstract}
Abstrak
Lembaga Pelatihan Pemerintah mempunyai tantangan yang sangat kompleks serta dituntut untuk menghasilkan SDM yang berkualitas. Dalam rangka peningkatan kapasitas dan kualitas SDM di Kementerian Kelautan dan Perikanan, Balai Diklat Aparatur Kementerian Kelautan dan Perikanan memiliki peranan penting dalam mendukung tercapainya visi dan misi serta penerapan nilai-nilai budaya kerja organisasi Kementerian Kelautan dan Perikanan. Salah satu langkah strategis yang dapat ditempuh oleh Balai Diklat Aparatur Kementerian Kelautan dan Perikanan adalah bertranformasi menjadi Corporate University (CorpU). Tujuan dari penelitian ini adalah menganalisis strategi Balai Diklat Aparatur Kementerian Kelautan dan Perikanan menuju CorpU. Analisis yang digunakan adalah analisis SOAR dengan melakukan perhitungan matriks IFE-EFE. Berdasarkan hasil analisis SOAR, Balai Diklat Aparatur Kementerian Kementerian Kelautan dan Perikanan, berada dalam kuadran strategi OA yaitu memanfaatkan peluang yang ada untuk mencapai hasil yang diharapkan dengan cara mengembangkan Learning Management System yang menjadi pusat integrasi seluruh manajemen pengetahuan dan pembelajaran di Balai Diklat Aparatur Kementerian Kelautan dan Perikanan.
\end{abstract}

Kata-kata kunci: CorpU, Analisis SOAR, Matriks IFE-EFE

\footnotetext{
Abstract

Government Training Institutions have very complex challenges and are required to produce quality human resources. In order to increase the capacity and quality of human resources in Ministry of Maritime Affairs and Fisheries, Apparatus Training Center of Ministry of Maritime Affairs and Fisheries has an important role in supporting the achievement of vision and mission and the application of the work culture values of the Ministry of Maritime Affairs and Fisheries. One of the strategic step that can be taken by Apparatus Training Center of the Ministry of Maritime Affairs and Fisheries is to transform into a Corporate University (CorpU). The purpose of this study is to analyze the strategy of Apparatus Training Center of Ministry of Maritime Affairs and Fisheries towards CorpU. This study use SOAR analysis by calculating the IFE-EFE matrix. Based on the result of SOAR analysis, Apparatus Training Center of Ministry of Maritime Affairs and Fisheries is in OA strategy quadrant which is to take advantage of existing opportunities to achieve the expected results by developing a Learning Management System that become a integration center of all knowledge and learning management adaot Apparatus Training Center of Ministry of Maritime Affairs and Fisheries.
}

Keyword: CorpU, SOAR Analysis, IFE-EFE Matrix 


\section{Pendahuluan}

Pembangunan SDM yang berkualitas menuju Smart ASN 2024 menjadi prorgam prioritas pemerintah secara nasional. Balai Diklat Aparatur KKP sebagai salah satu lembaga pelatihan pemerintah di bidang Aparatur Kementerian Kelautan dan Perikanan sudah saatnya untuk mengambil langkah strategis. Salah satu langkah yang tepat untuk ditempuh yakni mulai merancang konsep Corporate University (CorpU). Melalui CorpU yang merupakan salah satu strategi dalam mencapai tujuan organisasi ini diharapkan dapat mewujudkan link and match antara pembelajaran, pengelolaan pengetahuan dan penerapan nilai-nilai organisasi Kementerian Kelautan dan Perikanan yakni SAIL (Smart, Akuntable, Integritas, Loyalitas) sehinga dihasilkan postur SDM yang berkualitas. Definisi CorpU menurut Allen (2002) adalah setiap entitas pendidikan yang mempunyai metode strategis yang didesain untuk mengarahkan organisasinya untuk mencapai tujuan dengan cara melaksanakan aktifitas yang membantu perkembangan masing-masing individu, dengan pengelolaan modal insani dan manajemen pengetahuan (Knowledge Management) yang tepat. CorpU merupakan pembelajaran yang berfokus pada kebutuhan strategi organisasi dan kompetensi pegawai pada instansi.

$\begin{array}{cccc}\text { CorpU } & \text { sebagai salah satu mesin } \\ \text { strategis } & \text { organisasi } & \text { yang } & \text { dapat }\end{array}$ mengintegrasikan sumber daya, proses, dan SDM dalam pembelajaran, untuk terus bersinergi meningkatkan KSA (knowledge, skill, dan attitude) sehingga dapat memberikan kontribusi yang berarti untuk pencapaian target organisasi. Disinilah pentingnya lembaga pelatihan dan unit kepegawaian di setiap instansi pemerintah untuk dapat berperan mewujudkan CorpU, mengubah potensi ASN yang ada menjadi investasi sumber daya manusia aparatur yang bercirikan birokrasi kelas dunia yaitu profesional, percaya diri, multi skill dan otonom (Dwiyanto, 2015).

Tren CorpU di Indonesia bergerak lebih lambat daripada di Barat. Pada saat ini konsep CorpU ini mulai merambat ke sektor pemerintahan, terutama setelah diundangkannya UU 5 Tahun 2014 tentang ASN. Dalam Undang-Undang ASN tersebut serta peraturan-perundangan turunannya, konsep kompetensi PNS dirombak secara besar-besaran. Lembaga pelatihan milik pemerintah tidak lagi menyediakan menumenu pelatihan tertentu, namun harus menyesuaikan diri dengan kompetensi yang dimiliki oleh setiap individu ASN. Selain itu, berdasarkan UU ASN No. 5 Tahun 2014, bahwa pengembangan kompetensi merupakan hak bagi setiap ASN, minimal 20 jam pelajaran per tahun, dan diperkuat oleh Peraturan Kepala LAN No 10 Tahun 2014.

CorpU dibangun untuk menjawab kebutuhan perubahan metode belajar dalam melatih para pegawai agar dapat mengembangkan kompetensi ASN, serta menjalankan tugasnya dengan tepat dan efisien. Dalam menciptakan metode pembelajaran yang cepat, tepat dan akuntabel, dibutuhkan peran teknologi yang mendukung peran, tugas dan fungsi Balai Diklat Aparatur KKP agar berjalan dengan cepat, tepat, efektif, efesien, akuntabel, dan untuk menghasilkan target secara produktif baik dari sisi output maupun outcome.

Berdasarkan latar belakang yang disampaikan di atas, perlu dilakukan kajian dan analisis terkait strategi yang harus dipersiapkan dalam mewujudkan Balai Diklat Aparatur KKP sebagai CorpU. Dalam tulisan ini akan diulas tentang bagaimana strategi Balai Diklat Aparatur KKP menuju CorpU dilihat dari faktor internal dan eksteranl organisasi. Analisis yang digunakan adalah analisis Strategi SOAR. Diagram analisis SOAR merupakan diagram yang berfungsi untuk mengidentifikasi situasi dan posisi yang 
dihadapi oleh organisasi dalam persaingan bisnis menurut faktor internal yan dimiliki organisasi dan ekternal yang dihadapi organisasi sehingga dapat diciptakan harapan/mimpi yang ingin diraih (Stavros, Cooperrider, and Kelley, 2003).

Tujuan dari penulisan ini adalah memetakan strategi pengembangan Balai Diklat Aparatur KKP sebagai organisasi pembelajar menuju CorpU dengan mengidentifikasi berbagai faktor internal dan eksternal sehingga dapat dipetakan mengenai kekuatan dan peluang yang ada dalam mencapai hasil yang diharapkan dalam penyelenggaraan pendidikan dan pelatihan yang handal dalam menghadapi tantangan di era globalisasi saat ini. Manfaat penulisan ini adalah sebagai masukan bagi pimpinan dalam rangka transformasi Balai Diklat Aparatur KKP menjadi CorpU.

Menurut Allen (2002) dalam bukunya The Corporate University Handbook, definisi CorpU adalah any educational entity that is a strategic tool designed to assist its parent organization in achieving its goals by conducting activities that foster individual and organizational learning and knowledge. CorpU adalah seluruh hasil learning, training, \& knowledge yang mendukung langsung kepada performansi unit bisnis agar performansinya berkembang dan terus berkembang di atas perkembangan rata-rata industri. CorpU sebagai salah satu engine strategis organisasi yang dapat mengintegrasikan serta mentriangulasikan sumber daya, proses, dan SDM dalam pembelajaran, untuk terus bersinergi meningkatkan KSA (knowledge, skill, dan attitude) sehingga dapat memberikan kontribusi yang berarti untuk pencapaian target organisasi. Disinilah pentingnya lembaga pelatihan dan unit kepegawaian untuk dapat berperan mewujudkan CorpU, mengubah potensi ASN yang ada menjadi investasi sumber daya manusia aparatur yang bercirikan birokrasi kelas dunia yaitu profesional, percaya diri, multi skill dan otonom (Dwiyanto, 2015). Secara umum, CorpU dapat digambarkan sebagai suatu institusi pendidikan yang menciptakan personil yang kompeten untuk mendukung kinerja lembaga sesuai fungsinya dalam dunia yang bergerak dengan cepat. Akar kemunculan CorpU pada tahun 1985-an menurut Paton et.al (2004) adalah banyaknya keluhan bahwa universitas maupun sekolah umum tidak menyediakan tenaga yang memiliki kompetensi yang tepat, atau di tanah air sering sebut sebagai tidak siap pakai.

Menurut Aruman (2017) konsep CorpU berbeda dari konsep diklat, karena CorpU lebih mengacu pada program pengembangan SDM secara terarah dan sistematis, serta terkait dengan pencapaian visi-misi dan strategi suatu lembaga. Apabila lembaga pelatihan lebih berfokus pada menyediakan program untuk menutup kesenjangan kompetensi personil, maka CorpU lebih mengutamakan terjadinya perubahan yang mendasar pada kompetensi personil, atau disebut juga sebagai change management.

Stavros, Cooperrider, and Kelley (2003) menawarkan konsep SOAR (Strengths, Opportunities, Aspirations, Results) sebagai alternatif terhadap analisis SWOT, yang berasal dari pendekatan Appreciative Inquiry (AI). Pendekatan ini mulai dipopulerkan oleh David Cooperrider, dalam bukunya Introduction to AppreciativeInquiry (1995). Dikembangkan dalam kurun waktu kurang lebih 10 tahun, penelitian tentang SOAR akan membantu individu maupun organisasi dalam menentukan strategi dan mengerti kapasitasnya untuk meningkatkan tim, individu maupun performa organisasi. Tujuan adanya SOAR dikembangkan adalah untuk mengukur kapasitas individu dalam memikirikan strategi tentang empat elemen yang berfungsi dalam dinamika orientasi masa depan pada abad ke 21. Model SOAR 
mengubah analisis SWOT, yang sudah sangat mapan, dalam hal faktor-faktor kekurangan (weakness) internal organisasi serta ancaman (threats) eksternal yang dihadapinya ke dalam faktor-faktor aspirasi (aspiration) yang dimiliki perusahaan serta hasil (results) terukur yang ingin dicapai. Model analisis ini berpendapat bahwa faktor kekurangan dan ancaman dapat memunculkan perasaan negatif bagi para anggota organisasi, sehingga menurunkan motivasi mereka untuk berbuat yang terbaik. Dalam kerangka kerja SOAR, sebanyak mungkin stakeholder dilibatkan, yang didasarkan pada integritas para anggotanya. Masalah integritas menjadi sangat penting karena para stakeholder harus menyadari asumsi-asumsi yang menjadi dasar penggerak bagi para pemimpin organisasi. antara lain:

SOAR terdiri dari empat elemen,

1) Strength (S) merupakan segala hal yang menjadi kekuatan dan kemampuan terbesar yang dimiliki, berupa aset baik aset yang berwujud maupun aset yang tidak berwujud yang mampu mendukung keberlangsungan usaha. Kekuatan akan terus dikembangkan demi kemajuan organisasi maupun individu di masa depan.

2) Opportunities $(\mathrm{O})$ merupakan bagian dari lingkungan eksternal yang harus di analisis agar mudah memahami apa yang harus dilakukan agar dapat dimanfaatkan. Peluang akan memberikan manfaat bagi organisasi jika organisasi tersebut mampu meraih peluang tersebut dengan cepat dan tepat.

3) Aspirations (A) merupakan harapan, visi dan misi yang ingin dicapai guna membentuk kepercayaan diri terhadap produk, pasar dan hal apapun yang dikerjakan demi mencapai visi yang diharapkan sehingga muncullah perasaan positif dan semangat dalam meningkatkan kinerja serta pelayanan.
4) Results (R) merupakan hasil-hasil yang ingin dicapai dalam perencanaan strategis, guna mengetahui sejauh mana pencapaian dari tujuan yang telah disepakati bersama. Agar para anggota organisasi merasa termotivasi dalam usaha mencapai tujuan yang telah ditetapkan ini, maka perlu dirancang sistem pengakuan (recognition) dan reward yang menarik.

\section{Metode}

Makalah ini merupakan kajian literatur terhadap referensi dan dokumen yang tersedia dengan menggunakan analisis SOAR. Metode pengolahan dan analisis data yang digunakan adalah analisis deskriptif untuk mengidentifikasi posisi Balai Diklat Aparatur KKP sebagai organisasi pembelajar menuju CorpU. Analisis deskriptif digunakan untuk menganalisis lingkungan internal dan eksternal Balai Diklat Aparatur KKP berupa visi, misi, tujuan, kekuatan, peluang serta harapan dan hasil yang ingin dicapai oleh Balai Diklat Aparatur KKP. Sedangkan analisis kuantitatif menggunakan matrik External Factor Evaluation (EFE) dan matriks Internal Factor Evaluation (IFE). Kemudian setelah dilakukan perhitungan dalam matriks EFE dan IFE, akan diperoleh strategi yang paling tepat untuk diterapkan oleh Balai Diklat Aparatur KKP dalam berproses menuju CorpU.

\section{Hasil dan Pembahasan}

Balai Diklat Aparatur KKP memiliki fasilitas pelatihan berupa asrama, ruang kelas, perpustakaan, laboratorium (komputer, bahasa, aula, ruang makan, ruang ibadah, ruang olahraga, ruang karaoke, lapangan olah raga, akses internet serta layanan administratif untuk mendukung proses belajar mengajar yang efektif bagi peserta pelatihan. Balai Diklat Aparatur KKP mendukung visi dan misi Kementerian Kelautan dan Perikanan. 
Dalam rangka menuju CorpU tentunya ada berbagai upaya yang harus dilakukan antara lain adanya komitmen pimpinan tertinggi, internalisasi sikap/budaya organisasi, menyusun strategi pembelajaran CorpU, Infrastruktur TI yang mendukung CorpU, serta adanya Blueprint/Regulasi. Konsep perubahan Balai Diklat Aparatur KKP menjadi CorpU merupakan perubahan yang strategis. Perubahan

strategis meliputi perubahan budaya dan nilai-nilai dasar, perubahan arah/fokus bisnis, dan perubahan cara kerja. Perubahan strategis bersifat perubahan besar, fundamental, berdampak luas, dan memerlukan koordinasi dan dukungan unit-

\begin{tabular}{|c|c|c|c|}
\hline No & Aspek & Penjelasan & Kondisi \\
\hline \multirow[t]{2}{*}{1} & Jumlah Karyawan & Struktural dan Staff & 59 orang \\
\hline & & Widyaiswara & 16 orang \\
\hline \multirow[t]{4}{*}{2} & Sarana dan Prasarana & Tanah dan bangunan & $\begin{array}{l}\text { Balai Diklat Aparatur KKP } \\
\text { berdiri di atas tanah dengan luas } \\
35.751 \mathrm{~m}^{2}\end{array}$ \\
\hline & & Kapastitas kelas & Mampu menampung 160 orang \\
\hline & & Kapasitas asrama & Mampu menampung 142 orang \\
\hline & & $\begin{array}{l}\text { Sarana pendukung lain } \\
\text { (perpustakaan, } \\
\text { laboratorium, aula, masjid, } \\
\text { koperasi, sarana olah raga, } \\
\text { sarana hiburan, lapangan } \\
\text { olah raga) }\end{array}$ & Sudah memenuhi \\
\hline \multirow[t]{3}{*}{3} & Jenis Diklat & $\begin{array}{l}\text { Manajerial/ } \\
\text { Kepemimpinan }\end{array}$ & $\begin{array}{l}\text { Latsar CPNS, Diklat PIM IV, } \\
\text { Diklat PIM III }\end{array}$ \\
\hline & & Teknis & $\begin{array}{l}\text { Diklat teknis di bidang kelautan } \\
\text { dan perikanan }\end{array}$ \\
\hline & & Fungsional & $\begin{array}{l}\text { Diklat pembentukan jabatan } \\
\text { fungsional kelautan dan } \\
\text { perikanan }\end{array}$ \\
\hline 4 & Standarisasi/Akreditasi & Pelatihan Latsar CPNS & $\begin{array}{l}\text { Latsar CPNS Akreditasi B, } \\
\text { Diklatpim IV, III Akreditasi B }\end{array}$ \\
\hline 5 & $\begin{array}{l}\text { Manajemen Ilmu } \\
\text { Pengetahuan }\end{array}$ & $\begin{array}{l}\text { e-learning, e-jurnal, e- } \\
\text { library dll. }\end{array}$ & $\begin{array}{l}\text { Belum berjalan semuanya, hanya } \\
\text { e-learning yang sudah } \\
\text { dilaksanakan. }\end{array}$ \\
\hline
\end{tabular}

Sumber: Data Penulis, 2020 unit terkait atau bahkan seluruh komponen. Sedangkan perubahan operasional adalah perubahan kecil yang bersifat parsial dan tidak menimbulkan dampak luar biasa. Oleh karena itu, konsep perubahan dari Balai Diklat Aparatur KKP menuju CorpU harus menempuh jalur perubahan transformatif. Berikut disajikan kondisi aspek fisik dan non fisik Balai Diklat Aparatur KKP yang disajikan dalam Tabel 1 serta inventarisasi aspek-aspek CorpU yang disajikan dalam Tabel 2.

Tabel 1. Aspek Fisik dan Non Fisik Balai Diklat Aparatur KKP 
Tabel 2. Inventarisasi Aspek-aspek CorpU Balai Diklat Aparatur KKP

\begin{tabular}{|c|c|c|c|c|}
\hline No. & Nama Aspek & Penjelasan & Skor & Rekomendasi \\
\hline 1 & $\begin{array}{l}\text { Kapastisan dan } \\
\text { Kapabilitas manajemen }\end{array}$ & $\begin{array}{l}\text { Pengetahuan, keyakinan } \\
\text { dan komitmen pihak } \\
\text { manajemen mengenai } \\
\text { CorpU }\end{array}$ & 1 & $\begin{array}{l}\text { Perlunya peningkatan } \\
\text { kapasitas dan kapabilitas } \\
\text { diinisiasi dengan penjelasan } \\
\text { yang rinci }\end{array}$ \\
\hline 2 & $\begin{array}{l}\text { Moda-moda baru } \\
\text { pembentukan } \\
\text { pengetahuan dan } \\
\text { knowledge sharing }\end{array}$ & $\begin{array}{l}\text { Tersedianya media } \\
\text { komunikasi berbasis } \\
\text { digital E- Jurnal, E- } \\
\text { Learning, E- Library dan } \\
\text { lainnya }\end{array}$ & 1 & $\begin{array}{l}\text { Perlunya integrasi dalam } \\
\text { suatu Knowledge } \\
\text { Management System }\end{array}$ \\
\hline 3 & $\begin{array}{l}\text { Sistem untuk } \\
\text { mengetahui kebutuhan } \\
\text { pembelajar dan } \\
\text { menyediakan } \\
\text { kurikulum yang } \\
\text { memadai }\end{array}$ & $\begin{array}{l}\text { Pemetaan kompetensi } \\
\text { ASN, pembelajaran yang } \\
\text { disesuaikan dengan } \\
\text { kondisi kompetensi ASN }\end{array}$ & 1 & $\begin{array}{l}\text { Perlunya pemetaan } \\
\text { kompetensi agar terdapat } \\
\text { perencanaan pengembangan } \\
\text { kompetensi untuk individu } \\
\text { dan sertifikasi profesi }\end{array}$ \\
\hline 4 & $\begin{array}{l}\text { Kerjasama dan } \\
\text { networking dengan } \\
\text { stakeholder }\end{array}$ & $\begin{array}{l}\text { Pakar dan praktisi, } \\
\text { institusi untuk praktek, } \\
\text { magang, lembaga } \\
\text { tradisional, masyarakat } \\
\text { umum. }\end{array}$ & 2 & $\begin{array}{l}\text { Perlunya menjalin kerja sama } \\
\text { baik yang bersifat formal } \\
\text { maupun informal }\end{array}$ \\
\hline 5 & $\begin{array}{l}\text { Sistem pengawasan } \\
\text { dan evaluasi } \\
\text { pembelajaran }\end{array}$ & $\begin{array}{l}\text { Setiap individu harus } \\
\text { diketahui dampaknya } \\
\text { setelah pembelajaran } \\
\text { secara terukur dan } \\
\text { dilakukan evaluasi }\end{array}$ & 2 & $\begin{array}{l}\text { Perlu dirumuskan instrumen } \\
\text { dan sistem pengawasan } \\
\text { yang terukur }\end{array}$ \\
\hline 6 & $\begin{array}{l}\text { Teknologi } \\
\text { pembelajaran }\end{array}$ & $\begin{array}{l}\text { Sarana prasarana, } \\
\text { sistem digital, metode } \\
\text { pembelajaran yang } \\
\text { inovatif, blended- } \\
\text { learning }\end{array}$ & 1 & $\begin{array}{l}\text { Perlunya dilakukan } \\
\text { pengembangan teknologi dan } \\
\text { metode pembelajaran yang } \\
\text { inovatif }\end{array}$ \\
\hline 7 & $\begin{array}{l}\text { Inovasi dalam metode } \\
\text { Assesment }\end{array}$ & $\begin{array}{l}\text { Teknik-teknik baru dalam } \\
\text { assessment kompetensi } \\
\text { yang lebih sesuai (mis; } \\
\text { assessment di tempat } \\
\text { kerja, peer review, dll) }\end{array}$ & 1 & $\begin{array}{l}\text { Perlu dilakukan survey dan } \\
\text { benchmarking terkait jenis } \\
\text { assesment yang sesuai }\end{array}$ \\
\hline 8 & $\begin{array}{l}\text { Tersedianya atmosfer } \\
\text { pembelajaran yang } \\
\text { memberdayakan } \\
\text { (enabling) }\end{array}$ & $\begin{array}{l}\text { Pembelajaran } \\
\text { bersama, meliputi } \\
\text { sikap dan } \\
\text { pengetahuan fasilitator }\end{array}$ & 2 & $\begin{array}{l}\text { Perlu dilakukan survey } \\
\text { kualitatif mendalam secara } \\
\text { terbuka. }\end{array}$ \\
\hline 9 & Organisasi Pembelajar & $\begin{array}{l}\text { Sinergi, fokus pada } \\
\text { kekuatan invidu, }\end{array}$ & 1 & $\begin{array}{l}\text { Perlu dilakukan pengukuran } \\
\text { sejauh mana }\end{array}$ \\
\hline
\end{tabular}




$\begin{array}{ll}\text { mengutamakan } & \text { aspek-aspek } \\ \text { kepentingan lembaga } & \text { Learning } \\ \text { keterpaduan } & \text { Organization } \\ & \text { telah tersedia. }\end{array}$

Keterangan Skor: $0=$ tidak tersedia, $1=$ tersedia dalam jumlah terbatas, $2=$ tersedia namun tidak lengkap, 3 = tersedia seluruhnya namun kurang operasional; $4=$ tersedia seluruhnya dan berjalan dengan baik.

Sumber: Data Penulis, 2020

Formulasi strategi disusun berdasarkan analisis yang diperoleh dari penerapan SOAR Framework melalui tahapan-tahapan sebagai berikut :

a)

Membuat matriks internal-

eksternal

Matriks internal-eksternal ini dihasilkan pada saat pemetaan menggunakan SOAR Framework.

b) Memberikan bobot pada masing-masing faktor

c) Menghitung rating dan score masingmasing faktor

d) Menyusun faktor-faktor tersebut dalam kolom 1

e) Memberi pembobotan masing-masing faktor

f) Menghitung rating (untuk masingmasing faktor mulai dari 4 (outstanding) sampai dengan 1 (poor) berdasarkan pengaruh faktor tersebut terhadap kondisi organisasi

g) Mengalikan bobot dengan rating untuk memperoleh faktor pembobotan

h) Menjumlahkan skor pembobotan untuk memperoleh total skor.

\section{Perhitungan Bobot Internal dan Eksternal Menggunakan Analisis SOAR}

Perhitungan bobot internal dan eksteranl dimulai dengan mengidentifikasi kekuatan, peluang, harapan dan hasil sesuai kondisi di Balai Diklat Aparatur KKP. Identifikasi faktor internal dan eksternal dilakukan melalui diskusi dengan penyelenggara pelatihan. Data diperoleh dengan menyebarkan kuesioner kepada 5 orang penyelengara pelatihan. Berikut merupakan hasil perhitungan faktor-faktor internal dan eksternal yang berhasil diidentifikasi:

Tabel 3. Matriks IFE

\begin{tabular}{|c|c|c|c|c|}
\hline Kekuatan/Strength $(\mathbf{S})$ & $\begin{array}{c}\text { Data } \\
\text { Kuesioner }\end{array}$ & Bobot & Rating & Skor \\
\hline $\begin{array}{l}\text { Balai Diklat Aparatur KKP merupakan } \\
\text { satu-satunya Lembaga Pelatihan } \\
\text { Pemerintah yang bergerak di bidang } \\
\text { Kelautan dan Perikanan }\end{array}$ & 16 & 0,51 & 3 & 1,53 \\
\hline $\begin{array}{l}\text { Balai Diklat Aparatur KKP berpeluang } \\
\text { menyelenggarakan berbagai jenis } \\
\text { pelatihan dan sertifikasi, baik pelatihan } \\
\text { teknis, fungsional maupun manajerial } \\
\text { sesuai dengan kebutuhan. }\end{array}$ & 15 & 0,48 & 3 & 1,44 \\
\hline & 31 & $\mathbf{0 , 9 9}$ & & 2,97 \\
\hline Harapan/Aspirations (A) & Data & Bobot & Rating & Skor \\
\hline
\end{tabular}




\begin{tabular}{lccccc}
\hline \multicolumn{7}{c}{ Kuesioner } \\
\hline $\begin{array}{l}\text { Menjadi lembaga penyelenggaran } \\
\text { pelatihan di bidang Kelautan dan }\end{array}$ & 19 & 0,51 & 4 & 2,04 \\
Perikanan yang handal dan terpercaya & & & & \\
\hline $\begin{array}{l}\text { Terbangunnya Knowledge Management } \\
\text { System yang terintegrasi dengan } \\
\text { Learning Management System }\end{array}$ & 18 & 0,48 & 4 & 1,92 \\
\hline & & & & \\
\hline Total & $\mathbf{3 7}$ & $\mathbf{0 , 9 9}$ & $\mathbf{3 , 9 6}$ \\
\hline
\end{tabular}

Sumber: Data Penulis, 2020

Tabel 4. Matriks EFE

\begin{tabular}{lcccc}
\hline Peluang/Opportunities (O) & $\begin{array}{c}\text { Data } \\
\text { Kuesioner }\end{array}$ & Bobot & Rating & Skor \\
\hline $\begin{array}{l}\text { Program CorpU dibentuk sejalan dengan } \\
\text { prioritas pembangunan SDM serta grand }\end{array}$ & & 0,5 & 4 & 2 \\
design reformasi birokrasi nasional. & & & & \\
Kebijakan strategis pembangunan SDM & & & \\
ASN bertumpu pada reformasi & & & \\
manajemen ASN dalam UU Nomor & & & \\
$5 / 2014$ tentang ASN, PP Nomor 11/2017 & & & \\
tentang Manajemen PNS, dan PP Nomor & & & \\
49/2018 tentang Manajemen PPPK.
\end{tabular}

Revolusi Industri 4.0 memberikan 18

$0,5 \quad 4$
2 banyak kemudahan dalam proses belajar dan mengajar sehingga konsep Corporate University yang harus menerapkan prinsip: Applicable, Relevant, Impactful dan Accesible sangat mungkin dapat dilaksanakan.

\begin{tabular}{ccccc}
\hline & $\mathbf{3 6}$ & $\mathbf{1}$ & & $\mathbf{4}$ \\
\hline \multicolumn{1}{c}{ Hasil/Results (R) } & $\begin{array}{c}\text { Data } \\
\text { Kuesioner }\end{array}$ & Bobot & Rating & Skor \\
\hline $\begin{array}{l}\text { Tercapainya kompetensi SDM di bidang } \\
\text { Kelautan dan Perikanan }\end{array}$ & 17 & 0,48 & 3 & 1,44 \\
\hline $\begin{array}{l}\text { Meningkatnya kinerja SDM sehingga } \\
\text { tercapai visi dan misi organisasi }\end{array}$ & 18 & 0,51 & 4 & 2,04 \\
\hline \multicolumn{1}{c}{ Total } & $\mathbf{3 5}$ & $\mathbf{0 , 9 9}$ & & $\mathbf{3 , 4 4}$ \\
\hline
\end{tabular}

Sumber: Data Penulis, 2020 
Jurnal Pendidikan Kewarganegaraan

Vol. 7 No.1 Maret 2020

Total skor kekuatan/strength $\quad: 2,97$

Total skor peluang/opportunities : 4

Total skor harapan/aspirations $\quad$ : 3,96

Total skor hasil/results $\quad: 3,44$

Berdasarkan total skor diatas, kemudian dibuat diagram caretsius analisis SOAR yang didapatkan dari matriks IFE dan EFE sebagai berikut :

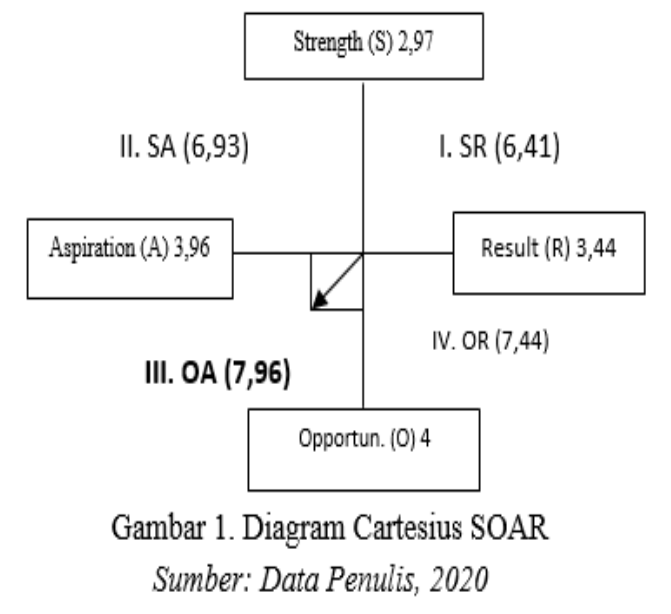

\section{Matriks SOAR}

Setelah didapatkan nilai total dari matriks IFE dan EFE yang digambarkan pada diagram cartesisu SOAR, kemudian didapatkan hasil rumusan kombinasi strategi OS,OA, SR dan AR dari ligkungan internal dan eksternal pada tabel di atas. Rumusan alternatif strategi merupakan suatu alternatif yang digunakan oleh Balai Diklat Aparatur KKP untuk menuju CorpU. Kombinasi strategi matrik yang didapat dari indikator dan dilakukan penggabungan pada faktor internal dan eksternal, hasilnya bisa dilihat di Tabel 5. Berdasarkan perhitungan tabel 5, diperoleh bahwa kuadran dengan nilai tertinggi adalah OA yakni 7,96. Artinya Balai Diklat Aparatur KKP dapat menciptakan strategi yag berorientasi kepada harapan yang ingin dicapai untuk memanfaatkan peluang yang ada. Strategi yang relevan untuk diterapkan adalah dengan melakukan benchmarking serta merancang pembuatan
LMS (Learning Management System) yang menjadi pusat integrasi seluruh manajemen pengetahuan dan pembelajaran di Balai Diklat Aparatur KKP untuk menjadikan Balai Diklat Aparatur KKP sebagai Center of Excellent. Namun dilihat dari faktor kekuatan, posisi Balai Diklat Aparatur KKP masih lemah dalam memanfaatkan kekuatan yang dimilikinya untuk mencapai hasil yang diinginkan. Sebenarnya terdapat peluang yang sangat tinggi bagi Pusdiklat untuk dapat berkembang dan berinovasi. 
Tabel 5. Penggabungan Faktor Internal dan Eksternal

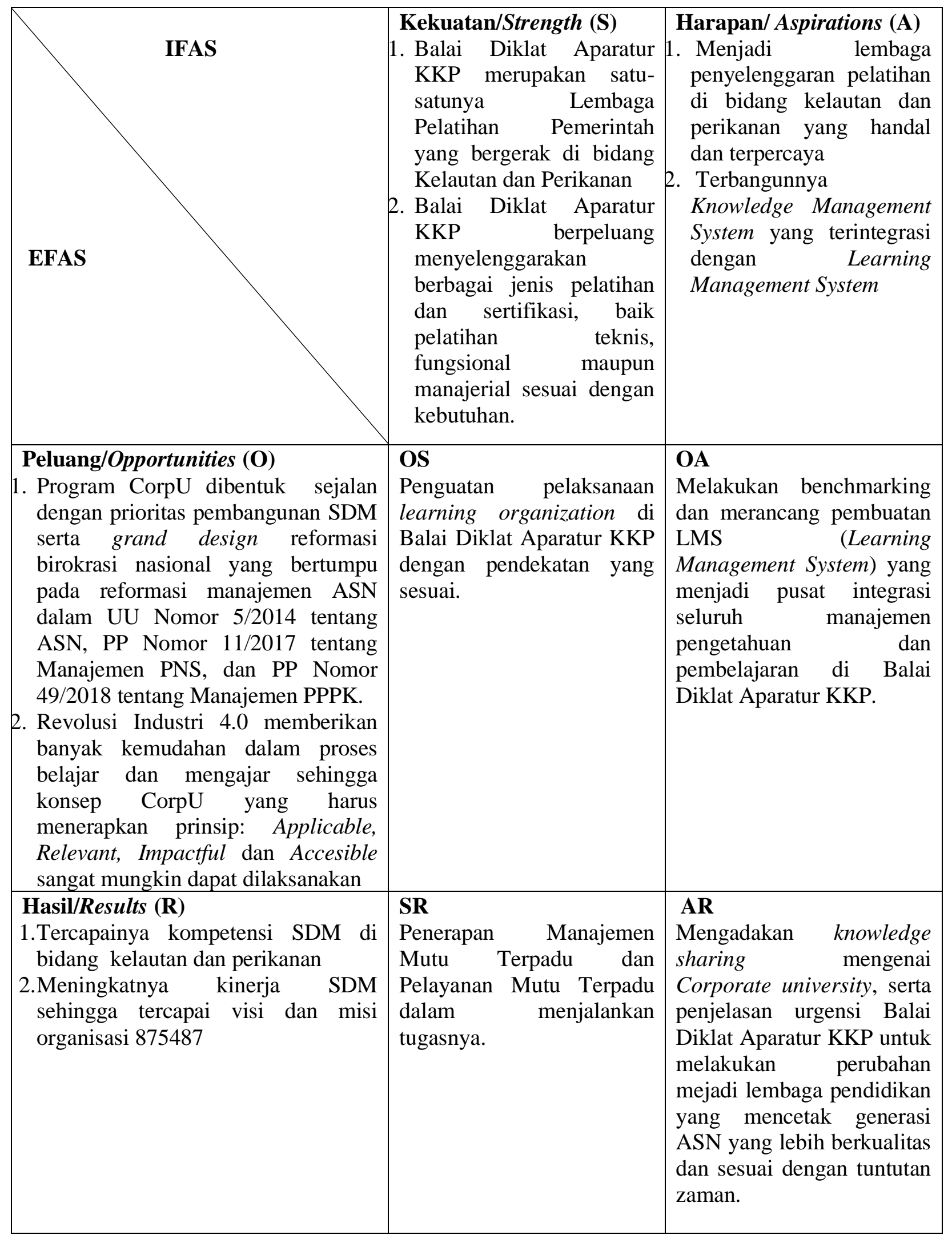

Sumber: Data penulis, 2020 


\section{Kesimpulan}

Ditinjau dari hasil inventarisasi baik aspek fisik maupun non fisik dapat terlihat bahwa hal-hal yang perlu menjadi perhatian lebih kepada aspek yang bersifat non fisik. Beberapa faktor non-fisik masih perlu dipersiapkan secara terukur dan terencana dengan baik, bahkan perlu dipetakan agar dapat diketahui titik ungkitnya, seperti: masalah sinergi, kapasitas dan kapabilitas, komitmen pemimpin, dan suasana pembelajaran yang memberdayakan. Beberapa pengukuran dan pemetaan lanjutan masih perlu dilakukan dengan menggunakan instrumeninstrumen penelitian yang sesuai. Di sisi lain, Balai Diklat Aparatur KKP memiliki potensi dan aset yang sangat besar untuk berkembang dan menjadi CorpU yang handal, profesional, dan terdepan.

Berdasarkan hasil analisis matriks matriks IFE dan EFE, Balai Diklat Aparatur KKP berada dalam matriks OA, artinya strategi yang paling relevan dilaksanakan saat ini adalah melakukan benchmarking terhadap lembaga pelatihan pemerintah lain yang sudah menjadi CorpU dan melakukan peancangan LMS agar seluruh kegiatan pembelajaran di Balai Diklat Aparatur KKP dapat terintegrasi dengan baik.

Setelah diperoleh hasil dan strategi yang relevan melalui analisis SOAR, Balai Diklat Aparatur KKP dapat melakukan peningkatan dan pengembangan serta penguatan learning organization dengan harapan Balai Diklat Aparatur KKP dapat menjadi Center of Excellent dalam menyiapkan SDM unggul di bidang Kelautan dan Perikanan sebagai cikal bakal menuju CorpU.
Dukungan pimpinan dan kerja sama seluruh elemen organisasi sangat diperlukan untuk menjadikan Balai Diklat Aparatur KKP sebagai oraginsasi pembelajar menuju CorpU.

\section{Referensi}

Allen, M.. 2002. The Corporate University Handbook. New York: AMACOM.

Aruman, E. 2017. Indonesia's Best Practice of Corporate University. Jakarta: PLN Corpu.

Dwiyanto, A. 2015. Mewujudkan Good Governance Melalui Pelayanan Publik. Yogyakarta: Gadjah Mada University Press.

Gonzales, D. 2017. Making of a Corporate University Model:Transition From Traditional Training to Learning Management System. Journal of Education and Practice, 8: (85-90).

Megawati, Rachman Nadya. 2019. Analisis Strategi Pusat Pendidikan dan Pelatihan Perdagangan Menuju Corporate University. Jurnal Cendekia Niaga, Vol. 3 No. 2: (7-28).

Paton, Rob., et al., 2005. Handbook of Corporate University Development. England: Gower Publishing Company.

Renstra Balai Diklat Aparatur KKP Tahun 2018-2020.

Stavros, J., Cooperrider, D., \& Kelley, D. L. (2003). Strategic inquiry appreciative intent: inspiration to SOAR, a new framework for strategic planning. $A i$ Practitioner, 11.

Yuliani, D. 2018. BPSDM Jawa Barat Menuju Corporate University:Sebuah Investasi Awal. Prosiding Seminar Nasional Inovasi Menuju Corpu, Edisi Khusus tahun 2018: (20-27). 


\section{Biarkan halaman ini tetap ada}

[ halaman ini sengaja dikosongkan ] 